\title{
Mixed climatology, non-synoptic phenomena and downburst wind loading of structures
}

\author{
G. Solari ${ }^{1}$ \\ ${ }^{1}$ Department of Civil, Chemical and Environmental Engineering (DICCA) \\ Polytechnic School, University of Genova \\ Via Montallegro, 1, 16145 Genova (Italy) \\ giovanni.solari@unige.it
}

\begin{abstract}
In 1961 Davenport published a paper, considered by most the constitutive deed of Wind Engineering, where meteorology, micrometeorology, climatology, aerodynamics and structural dynamics were embedded into a homogeneous framework of the wind loading of structures. This scheme, known as the "Davenport chain" and referred to a synoptic-scale extra-tropical cyclone is so limpid and elegant as to become a sort of axiom. Between 1976 and 1978 Gomes and Vickery separated thunderstorm from non-thunderstorm winds, determined their extreme distributions and derived a mixed statistical model later extended to other phenomena; this study, a milestone in the emerging issue of mixed climatology, proved the impossibility of labelling a heterogeneous range of phenomena characterized by different velocity fields, frequencies, durations and extensions by the generic term "wind". Many of these phenomena occur in limited and well-known areas. Extra-tropical cyclones and thunderstorms affect the entire planet. This paper provides a state-of-the-art of this subject, with particular regard to the studies conducted at the University of Genova on thunderstorms.
\end{abstract}

Keywords: downburst, extra-tropical cyclones, mixed climatology, non-synoptic phenomena, thunderstorms, wind loading of structures.

\section{Introduction}

Cermak (1975) defined wind engineering as "the rational treatment of the interactions between wind in the atmospheric boundary layer and man and his works on the surface of Earth". The International Association for Wind Engineering (IAWE) promotes international co-operation among scientists, engineers and professionals for the advancement of knowledge in the broad field of Wind Engineering (Solari, 2007).

The complex process that transformed a heterogeneous set of distinct topics related to wind into a homogeneous and autonomous discipline originated in the first half of the 20th century from a series of studies concerning the wind loading of structures. Pagon $(1934,1935)$ published eight papers on the Engineering News Records that transferred a synthesis of the knowledge in meteorology and aerodynamics to civil 
engineering. Karman (1948) delivered a lecture at the Société des Ingenieurs Civils de France in which he described the many applications and perspectives of aerodynamics in the engineering and industrial fields. The American Society of Civil Engineers (1961) collected six papers that offer the first state-of-the-art on wind forces on structures. In the same year Davenport (1961) published a paper, considered by most the constitutive deed of wind engineering, where the concepts of meteorology, micrometeorology, climatology, aerodynamics and structural dynamics were embedded into a homogeneous framework of the wind loading of structures. This scheme, now known as the "Davenport chain", opened new and unlimited prospects to the comprehension and calculation of the dynamic response of wind-sensitive structures creating, since then, a growing interest of structural engineering towards this matter.

At the same time this paper was a sort of straitjacket in which wind engineering was trapped for many years. The wind model conceived by Davenport and on which its entire treatment is based refers to an extra-tropical cyclone at the synoptic scale. In such framework the mean wind velocity, usually horizontal, is characterized by a vertical profile in equilibrium with an atmospheric boundary layer whose depth is in the order of $1-3 \mathrm{~km}$; here, within time intervals between 10 minutes and 1 hour, the turbulent field is dealt with as stationary and Gaussian. This reference model is so clear and elegant has to become, over the years, an axiomatic base to which wind engineering was often inspired in an uncritical way.

Curiously, Davenport (1968) himself published a new fundamental paper that ends with a prophetic viewpoint on intense local storms: "In formulating wind statistics, the question has been posed as to whether intense local storms including tornadoes and thunderstorms conform to the wind structure of large scale storms. Tornado probability is an order of magnitude different from other storm winds. A design approach based on fail-safe concepts is indicated. The question of thunderstorms is less clear cut. In certain parts of the world it appears that a significant proportion of maximum gusts arise from thunderstorms. Wittingham (1964) in his analysis of Australian wind conditions shows that as much as $50 \%$ of maximum winds occur in thunderstorms. These storms may last 5-10 minutes and subside rapidly during which time severe convective turbulence may induce strong gusts. From the design point of view, the question is probably best treated by adopting an approach in which the mean velocities are obtained for intervals short enough to reflect the higher winds prevalent in the thunderstorm and assume turbulence response characteristic of other major storms. Eventually, it may be possible to treat thunderstorms separately and if significantly different properties are found and prove important design accordingly." These concepts were taken up by Gomes and Vickery between 1976 and 1978. They first carried out a novel study of the extreme wind velocity in Australia (Gomes and Vickery, 1976), in which they separated thunderstorm from non-thunderstorm winds, determined the extreme distributions of these two phenomena and derived a mixed statistical model later extended to other phenomena of different nature (Gomes and Vickery, 1977/1978); this latter paper is a milestone for the emerging issue of mixed climatology. Far beyond the separation of data related to different phenomena for the statistical analysis of the extreme wind speed, it stated the impossibility of labelling with the generic term "wind" a varied and heterogeneous range of phenomena en- 
dowed with different wind velocty fields, frequencies, durations and extensions. Many of them - tropical cyclones, tornadoes, monsoons, katabatic and down-slope winds - occur in relatively small and well-known areas. Extra-tropical cyclones and thunderstorms affect almost all countries at mid-latitudes.

This paper provides a short introduction to thunderstorms and downbursts in the framework of mixed climatology and non-synoptic phenomena (Section 2), a stateof-the-art of the studies developed world-wide (Sections 3-7), and a brief illustration of the research projects carried out at the University of Genova (Section 8). In the light of the huge number of papers published in this field, the references (Section 9) furnish a limited and non-exhaustive panorama of this matter.

\section{Thunderstorms and Downbursts}

The attention of mankind towards thunderstorms dates back to antiquity. Anassimandro of Mileto (610-546 B.C.) wrote Della Natura, where he argued that "thunders in thunderstorms are due to the shear among clouds". In De Rerum Natura (60 B.C.), Titus Lucretius Cares wrote that "the energy source of tornadoes and wind storms is represented by the electric forces in the air. Similar concepts were exposed by Lucius Anneus Seneca in Les Quaestiones Naturales (41 A.D.), where he wrote that "the flare is caused by the shear of the clouds and the lightning is produced when they enter violently into contact with each other. Both wind storms and thunderstorms have their origin in clouds that burst or explode".

After writing Discourse concerning the origins and properties of wind (1671) Ralph Bohun discussed the formation of storm clouds and their ability to produce tornadoes and "violent air explosions that are almost perpendicular to earth". Benjamin Franklin first detected the electricity of thunderstorms (1752) by means of kites and determined the link between lightning and energy. On his tracks, John Charles Peltier stated that all intense wind storms are caused by air electricity (Meteorologie, 1840). In the same year James Pollard Espy published The Philosophy of Storms (1840), claiming that "ascending columns carry water vapour they contain, and if they rise sufficiently, the cold produced by the expansion causes condensation of vapour in clouds. (...) As soon as clouds begin to form, the latent heat liberated from condensation originating from a violent expansion of the air, that is, a wind storm". William Ferrell first illustrated the occurrence of an ascending current, its rising energy and condensation, the copious precipitations, and the appearance of a descending current in A popular treatise on the winds (1889). John Park Finley (1889) sustained that "of 473 cases in which the atmospheric conditions preceding tornadoes were observed, 410 were violent thunderstorms".

In 1925, public opinion was troubled by the crash in U.S. of the Shenandoah Airship during a thunderstorm, which caused the death of many passengers. This disaster favoured the development of a vast literature, also stimulated by the awareness that a better knowledge of thunderstorms would have had a strategic importance for the growth of civil aviation and for the evolution of war strategies. 
This led to se*veral projects, the most important of which, Thunderstorm Project (1946-1949) gave rise to the first modern model of a thunderstorm (Byers and Braham, 1949). It is a mesoscale phenomenon that develops in a few kilometres on the horizontal and consists of a set of cells that evolve through three subsequent stages in about 30 minutes: the cumulus stage, due to convective unstable phenomena, originates an updraft of warm air that gives rise to a large size cumulus; the mature stage, in which the cumulus becomes a cumulonimbus and, while the updraft is still present, a downdraft of cold air occurs; and the dissipating stage, in which the thunderstorm is first dominated by the downdraft, then it losses force and disappears.

Fujita $(1985,1990)$ contributed to the knowledge of thunderstorms, showing that the downdraft that impinges over the ground produces intense radial outflows and ring vortices. The whole of these air movements is called downburst and is divided into macro-burst and micro-burst depending on their size. These led to three projects NIMROD (1978), JAWS (1982) and MIST (1986) - which provided an unprecedented amount of data. On the one hand, they showed that the radial outflows of a downburst are characterized by non-stationary velocity fields with a "nose profile" that increases up to 50-100 m height, then decreases above (Fig. 1). On the other hand, they generated an extraordinary fervour of research in atmospheric sciences, focusing on the causes, morphology and life-cycle of thunderstorms (Goff, 1976; Hjemfelt, 1988).

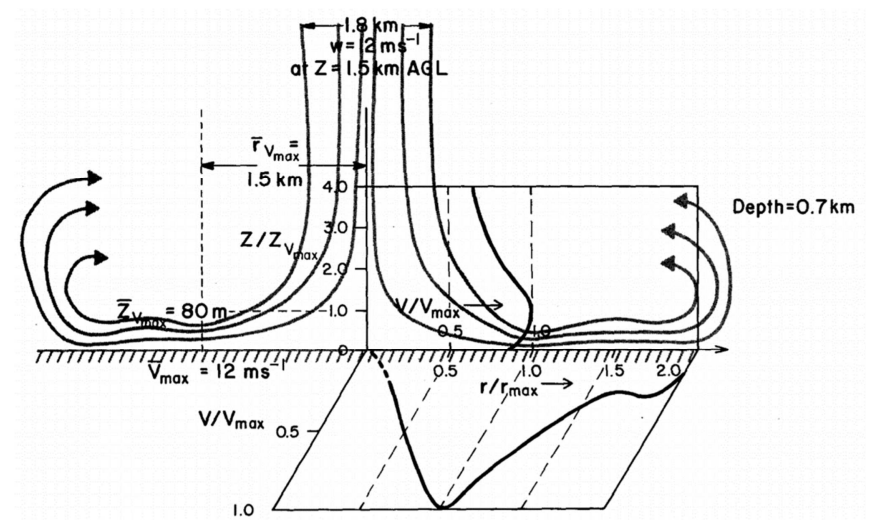

Fig. 1: Thunderstorm downburst and nose velocity profile in the radial outflow (Goff, 1976)

In the same period, wind engineering realized that the design wind speed is often due to thunderstorm outflows and they therefore have a focal role on structural safety (Letchford et al., 2002). Hence, a striking research arose, oriented to five main directions (Solari, 2014): 1) wind statistics, precursors and climate change; 2) wind detection and measurements; 3) wind modelling and simulation; 4) wind loading of structures; 5) wind-excited structural response.

Despite this reality this matter is still dominated by huge uncertainties and there is not yet a shared model for thunderstorm outflows and their actions on structures like the one formulated by Davenport (1961) over half century ago for synoptic cyclones. Yet, there is no rational framework in which the wind actions due to cyclones and thunderstorms are embedded. This happens because the complexity of thunderstorms 
makes it difficult to establish physically realistic and simple models. Their short duration and small size make a limited data available. The gap between research in wind engineering and atmospheric sciences exacerbates this reality. Therefore, the wind loading of structures is still evaluated by Davenport's model at the most considering thunderstorms, if the data is available, in the statistical evaluation of the extreme wind speed. This is not enough, however, because cyclones and thunderstorms are different phenomena that need separate assessments (Solari, 2014).

\section{Wind Statistics, Precursors and Climate Change}

Taking a leaf from the papers by Gomes and Vickery $(1976,1977 / 1978)$ the study of the extreme wind speed in thunderstorm outflows and mixed climates was prosecuted by Riera et al. (1977), Riera and Nanni (1989), Twisdale and Vickery (1992), Choi and Tanurdjaja (2002), Lombardo (2014), and Mohr et al. (2017).

The role of the downdraft size and of the touch-down position in the probability of occurrence of a downburst at a point or along a line, in particular a transmission one, was examined first by Oliver et al. (2000) and by $\mathrm{Li}$ (2000).

The extraction and classification criteria for separating thunderstorm from nonthunderstorm winds without making recourse to a systematic survey of the weather scenarios in which storms occur was elucidated by Choi (1999), Kasperski (2002), and Lombardo et al. (2009), who implemented semi-automated procedures to carry out this delicate but essential operation.

A lot of research has been also devoted to precursors or indexes (Lifted Index, Showalter Index, Total Totals, K Index, SWEAT, Bulk Richardson number, CAPE, WINDEX) that may provide elements to identify the weather conditions in which the probability of occurrence of thunderstorms increase (McCann, 1994; Huntrieser et al., 1997; Haklander and Van Delden, 2003; De Coning et al., 2011).

Of course, climate changes play a crucial role in all the above topics. In a field still dominated by many uncertainties and diversity of viewpoints (Giorgi et al., 2001; Marsh et al., 2009; Nissen et al., 2013; Jacob et al., 2014; Púcik et al., 2017), the opinion that thunderstorms and downbursts are increasing in frequency and intensity seems to be quite shared.

\section{Wind Detection and Measurements}

The study of the phenomenology of thunderstorms and of their wind fields received great impulse from the evolution of the detection and measurement systems - mainly anemometers installed on antenna masts, radar doppler, LidARS, and aircrafts instrumented for meteorological surveys. After the pioneering monitoring campaigns carried out for the projects NIMROD, JAWS, and MIST (Fujita, 1990), the literature on this topic exhibited two complementary pathways. 
On the one hand, a research line was developed, of meteorological imprint, which studies the causes, morphology and life-cycle of thunderstorms also with regard to their classification (Goff, 1976; Fujita and Wakimoto, 1981; Wilson et al., 1984; Hjemfelt, 1988; Brooks et al., 2003).

On the other hand, in a typical wind engineering spirit, there was a proliferation of measurements and interpretations of downburst according to signal analysis and models providing key elements for the wind loading of structures (Choi and Hidayat, 2002a; Choi, 2004; Chen and Letchford, 2006, 2007; Duranona et al., 2006; Holmes et al., 2008; Lombardo et al., 2014; Gunter and Schroeder, 2015).

\section{Wind Modelling and Simulation}

The modelling and simulation of downbursts is carried out by laboratory tests, CFD simulations, analytical methods and Monte Carlo techniques.

\subsection{Laboratory Tests}

Laboratory tests may be classified in three main families involving fluid release method, impinging wall jet technique, and the use of modified or new facilities.

The first family, pioneered by Lundgren et al. (1992) and Alahyari and Longmire (1995), involves the release of a liquid mass into a body of less dense liquid; this simulates the effects of buoyancy and produces a ring vortex, favouring the study of the morphology and of the physics of downbursts. It is limited to small geometric and velocity scales, not suitable to determine the wind loading of structures.

The second family involves a jet that impinging on a flat surface creates a wall radial outflow. The first impinging wall jet tests were carried out by Bakke (1957) to investigate experimentally the theory formulated by Glauert (1956). Advances in this technique are reported by Poreh et al. (1967), Donaldson and Snedeker (1971), Didden and Ho (1985), and Wood et al. (2001). Chay and Letchford (2002) first studied the downburst by a stationary wall jet simulation, then realized an equipment to reproduce the effects of the downburst translation (Letchford and Chay 2002). Richter et al. (2018) simulated the downburst by embedding the impinging wall jet into a boundary layer flow. Scaling criteria for model experiments and full-scale conditions are discussed by Xu and Hangan (2008) and by McConville et al. (2009).

The third family involves the techniques that modify the traditional axial flow of a wind tunnel in order to simulate the outflow of a downburst. This family includes the pulsed wall jet method (Mason et al., 2005), the stationary and non-stationary slot jet technique (Lin and Savory, 2006; Lin et al., 2007), the generation of gust fronts by a multiple fan wind tunnel with individually controlled fans (Cao et al., 2002), and the use of shutter mechanisms (Matsumoto et al., 2007). Hangan et al. (2017) describe some large-scale laboratories recently developed in the wind engineering field, focusing on the simulation of tornadoes and downbursts at the WindEEE Dome. 


\subsection{CFD Simulations}

Likewise laboratory tests, also CFD simulations may be classified into three main groups referred to as the full-cloud models, the sub-cloud models, and the impinging wall jet technique.

Full-cloud models simulate the whole region, the life cycle and the microphysical processes involved by thunderstorms. The first ones, appeared in 2-D version in the '60s (Ogura, 1963; Orville, 1965) and in 3-D version in the '70s (Steiner, 1973), were conditioned by the computational limits and by the scarcity of observed data. The situation improved in the mid ' 80 s, thanks to the evolution of computing power and to first experimental campaigns. Among others, the 3-D model named Terminal Area Simulation System (TASS) (Proctor, 1987a, 1987b) and the studies carried out by Hjelmfelt et al. (1989), Knupp (1989) and Straka and Anderson (1993) deserve mention. Nicholls et al. (1993) simulated the actions induced by a downburst on a building by a multi-scale LES 3-D model.

Sub-cloud models waive to simulate the whole thunderstorm to focus on near-ground flow dynamics, i.e. on the domain of major interest for engineering. They are driven by a sort of thermal forcing, imposed under the cloud at an elevated region of the domain, which simulates the microphysical cooling processes. This method, introduced by Mitchell and Hovermale (1977), was developed by Proctor $(1988,1989)$, Straka and Anderson (1993), Orf and Anderson (1999), Mason et al. (2009), and Vermeire et al. (2011). Orf et al. (2012) pointed out that computational advances will allow the use of full-cloud models also for wind engineering applications.

The impinging wall jet technique replicates the corresponding laboratory tests by CFD simulations. They have similar properties to sub-cloud models because waive to simulate the whole thunderstorm to focus on the near-ground flow field; diversely from sub-cloud models, however, the forcing source is not thermal but mechanical. This method, introduced by Selvam and Holmes (1992), was developed later by Wood et al. (2001), Kim and Hangan (2007), and Vermeire et al. (2011). Zhang et al. (2013) carried out systematic comparisons between the results provided by the impinging jet model, the cooling sorce model and full-scale measurements. Aboshosha et al. (2015) used LES to improve the simulation of turbulence.

\subsection{Analytical Models}

Analytical models get leverage from measurements, experiments and simulations. They initially applied basic fluid dynamic laws to stationary flows, in order to obtain simplified analytical expressions, independent of time, of the vertical and radial components of the wind velocity. This led to the impinging wall jet (Oseguera and Bowles, 1988) and to the vortex ring (Zhu and Etkin, 1985; Ivan, 1986; Vicroy, 1992) models. Holmes and Oliver (2000) developed the impinging jet model providing a simplified expression of the radial component of the wind speed as a function of the distance from the jet axis and of the time; they also expressed the horizontal velocity as the vector sum of the stationary radial velocity and of the translational or 
background velocity of the downburst. Li et al. (2012) and Abd-Elaal et al. (2013a) proposed analytical models of the vertical and radial profiles of the horizontal and vertical components of the wind speed that take into account the non-linear growth of the surface boundary layer. Abd-Elaal et al. (2013b) used a coupled parametricCFD model to reconstruct the downburst age and evolution based on measures.

The turning point in this topic is represented by a paper in which Choi and Hidayat (2002b) expressed the instantaneous wind velocity as the sum of its time-varying mean part, averaged over a suitable moving period, plus a zero mean fluctuation dealt with as a stationary random process. This approach was developed later by Chen and Letchford (2004a, 2006, 2007), who expressed the time-varying mean part of the wind velocity as the product of a function depending on space, provided by the previous time-independent analytical models, by a function slowly varying on time; regarding the fluctuation, dealt with as non-stationary, this was given by the product of its time-varying standard deviation by a random stationary Gaussian process with zero mean and unit standard deviation, whose spectral properties were expressed by the classical models adopted for synoptic wind speeds. New advances are reported by Chay et al. (2008). Huang and Chen (2009) represented the fluctuation by wavelet transforms and evolutionary spectra. Ponte and Riera (2010) merged these models into a Monte Carlo algorithm aiming to provide the distribution of the maximum velocity in mixed climates.

\subsection{Monte Carlo Techniques}

Based on the above analytical models, many papers have been developed to represent or simulate transient wind fields. Wang et al. (2013) conceived a data-driven approach to simulate downburst wind speeds by Hilbert transform, stationary wavelet transform, and Proper Orthogonal Decomposition (POD). Wang et al. (2014) and Huang et al. (2015) used discrete wavelet transform and kernel regression to infer the time-varying mean and variance of non-stationary wind speeds, respectively. Peng et al. (2017) simulated multi-variate non-stationary wind fields along lines with uniformly distributed nodes, by hybrid stochastic waves and POD factorization.

\section{Wind Loading of Structures}

The study of the wind loading of structures aiming to take into account the transient nature of the oncoming flow field may be framed into two families of methods.

The first one, not strictly related to downbursts and mainly focused on the fundamentals of transient aerodynamics, involves almost exclusively laboratory tests on slender reference elements (Sarpkaya, 1963; Katsura, 1997; Matsumoto et al., 2007). The second group, concerning 3-D bluff-bodies, avails itself of laboratory tests, CFD simulations and full-scale measurements. Starting from the pioneering papers by Chay and Letchford (2002) and Letchford and Chay (2002), Sengupta et al. (2008) 
simulated the wall jet both in wind tunnel and through CFD to determine the wind loading on a cubic building. Zhang et al. (2013) and (2014) carried out wind tunnel tests on low- and high-rise buildings, respectively, by the impinging wall jet technique. Jesson et al. (2014) performed similar tests on the roofs of several building types. Lombardo and Mason (2016) reported full-scale measurements of the loading due to a downburst on the low-rise laboratory building at the Texas Tech University.

\section{Wind-Excited Response of Structures}

The research activity on the wind-excited response of structures to thunderstorm outflows concerns two main topics: idealized reference systems and real structures.

Idealized reference systems are studied, as it is typical of structural dynamics, to formulate general models and to inspect the role of model parameters. Choi and Hidayat (2002) studied for the first the wind-induced response of a Single-Degree-OfFreedom (SDOF) system to thunderstorm outflows identically coherent in space, in order to generalize the classical gust response factor technique for synoptic events. This approach was developed by Chen and Letchford (2004b), who analyzed a SDOF system through a so-called Maximum Dynamic Magnification Factor, given by the ratio between the maximum value of the dynamic response and the static response to the peak loading, and by Chay et al. (2006), who applied a time-domain approach based on ARMA simulations. Chen (2008) studied the dynamic response of a building to a transient wind field modelled by an evolutionary power spectral density (EPSD). Kwon and Kareem (2009) proposed a gust front factor framework where the original gust response factor technique was generalized from stationary to non-stationary wind actions by an EPSD approach. Le and Caracoglia (2015) adopted the Wavelet-Galerkin method to evaluate the non-linear and/or non-stationary response of SDOF and NDOF systems. Chen (2015) investigated the multimode coupled buffeting response of long-span bridges by EPSD. Kareem et al. (2016) depicted a generalised wind loading chain for non-stationary events, using wavelets or EPSD. Wang et al. (2017) studied the buffeting response of a hinged overhead transmission conductor. Peng et al. (2018) developed an EPSD approach including a time-varying coherence function.

The analysis of real structures is mainly addressed to transmission lines and towers, the structural types that suffer the largest damage and collapse due to thunderstorms. In this framework, thunderstorms are often simulated by CFD codes whose output is transformed into aerodynamic loads applied to finite element structural models (Shehata et al., 2005; Darwish et al., 2010; Yang and Hong, 2016; Mara et al., 2016). Aeroelastic wind tunnel tests on a transmission line model at the WindEEE Dome are described by Elawadi et al. (2017). Preliminary results of full-scale measurements carried out in Germany are reported by Stengel and Klaus (2017). 


\section{Thunderstorm Research at the University of Genova}

\subsection{WP and WPS Projects}

The research on thunderstorms at the University of Genoa originated from two European Projects - "Wind and Ports" (WP) (Solari et al 2012) and "Wind, Ports and Sea" (WPS) (Repetto et al 2017) - financed by the European Cross-border program "Italy-France Maritime 2007-2013". They handled the wind safe management and risk assessment of the main commercial ports in the High Tyrrhenian Sea. This aim was pursued by creating an integrated set of tools including an extensive monitoring network, multi-scale numerical models, medium- and short-term forecast algorithms, and statistical analyses. The results are made available to port operators through an innovative Web GIS platform (Repetto et al 2018).

The WP and WPS network is made up of 28 ultrasonic anemometers, distributed in the Ports of Genoa (2), La Spezia (6), Livorno (1), Savona (7), Bastia (5) and L'île Rousse (2), 3 LiDAR wind profilers, and 3 weather stations, each including another ultrasonic anemometer, a barometer, a thermometer and a hygrometer.

The ultrasonic anemometers detect the wind speed and direction with a precision of $0.01 \mathrm{~m} / \mathrm{s}$ and 1 degree, respectively. Their sampling rate is $10 \mathrm{~Hz}$ with few exceptions. Sensors are mounted on high-rise towers and on some antenna masts at the top of buildings, at least at $10 \mathrm{~m}$ height above ground level (AGL). The LiDAR profilers detect the 3 components of the wind speed at 12 heights between 40 and $250 \mathrm{~m}$ AGL, with a sampling rate of $1 \mathrm{~Hz}$. A set of local servers receives the data detected in their own port area and automatically sends it to the central server in DICCA at UNIGE, where they are checked and stored in a database.

\subsection{Wind Speed Analysis}

The data detected by the WP and WPS network shows the presence of records due to different wind phenomena, namely extra-tropical cyclones, thunderstorm outflows and intermediate events. Thus, in order to focus on intense thunderstorm outflows, a semi-automatic procedure was implemented to extract these events (De Gaetano et al., 2014) without carrying prohibitive meteorological surveys. First, 93 records labelled as thunderstorm outflows were extracted (Solari et al., 2015a). Then, on increasing the available data, 247 non-stationary records were gathered (Zhang et al 2018a). All records were subjected to extensive probabilistic analyses aiming at evaluating their main properties relevant to the wind loading of structures.

Despite this procedure has the capability of detecting the presence and the characteristics of intense transient events based on sole anemometric measures, the knowledge of the weather scenarios that occur during these events would be very useful to confirm the meteorological nature of the gust fronts classified as thunderstorms. With this aim, the event occurred in Livorno on 1st October 2012 was cho- 
sen as a test case (Burlando et al., 2017) and studies were carried out of the atmospheric conditions concurrent with it by gathering model analyses, standard in-situ data, remote sensing, proxy data and visual observations. This information lead to reconstruct the weather scenario, to classify this event as a wet downburst, and to determine its space-time evolution.

In the meanwhile, relying on the acquisition of over 6 years of measurements at several anemometers, preliminary estimates of the extreme peak wind speed distribution were carried out (Zhang et al., 2018b). These confirm, as in many parts of the world, that the most intense wind events that occur in the High Tyrrhenian Sea area are due to thunderstorms. Besides, gathering the ensemble of all the extreme speed values into a unique dataset leads to underestimating the mixed distribution especially for high return periods, where it tends to coincide with the thunderstorm one.

\subsection{Wind Loading and Response of Structures}

The study of the loading and response of structures started from the consideration that thunderstorms are transient phenomena with short duration and the response to these phenomena, most notably to earthquakes, is usually evaluated by the response spectrum technique. Accordingly, a "new" method was stated that generalises the "old" response spectrum technique from earthquakes to thunderstorms.

Firstly, this problem was formulated for a point-like SDOF system (Solari et al., $2015 \mathrm{~b}$ ), proving that the equivalent static loading is the product of the peak wind force by a non-dimensional quantity, the thunderstorm response spectrum, depending on the fundamental frequency and on the damping ratio.

Then, this method was generalized to a MDOF system (Solari, 2016) subjected to a partially coherent wind field. The structure was modelled as a slender vertical cantilever beam whose dynamic response depends on the sole first mode of vibration. Analyses encapsulated the generalised equivalent wind spectrum technique (Piccardo and Solari, 1998), a method by which a multi-variate stationary wind field is replaced by an equivalent mono-variate one. The equivalent static force is the product of the peak wind loading by a non-dimensional quantity, the equivalent response spectrum, depending on the first frequency, on the damping ratio and on a size factor.

To check and refine the thunderstorm response spectrum technique, time domain analyses were carried out based on a novel hybrid simulation strategy (Solari et al., 2017) that captures the inherent properties of the thunderstorm outflows through simple physical concepts and real velocity records. It consists in assembling the different component signals that make up the wind velocity model, taking into account their sources of randomness. The time-domain integration of the equations of motion shows that the density function of the maximum value of the response to thunderstorm outflows is more spread than that due to synoptic cyclones. Thus, differently from the classic wind excitation, it is not appropriate to identify the maximum value of the response with its mean value. 


\subsection{The ERC THUNDERR Project}

Realized in an area well-known for its violent convective activity and its often dramatic outcomes, the WP and WPS network produced an unprecedented dataset of transient records. This inspired the Project THUNDERR - Detection, simulation, modelling and loading of thunderstorm outflows to design wind-safer and costefficient structures - awarded by an Advanced Grant (AdG) 2016 of the European Research Council (ERC) under Horizon 2020. It pursues three aims.

The first objective concerns the thunderstorm as a physical phenomenon. It aims to formulate a unitary model that may represent a novel result for atmospheric sciences and a sound basis for assessing realistic wind loading of structures. This will be pursued by strengthening the WP and WPS network through other instruments at the frontier of current technology, by conducting large-scale tests in the WindEEE Dome at the University of Western Ontario, Canada (Hangan et al., 2017) and small-scale ones in other laboratories, by performing CFD simulations with the Technical University Eindhoven, Netherlands (Blocken, 2014), by studying the weather scenarios in which thunderstorms occur and their damage with the Freie Universität Berlin, Germany (Nissen, 2014) and with the European Severe Storm Laboratory (Púcik et al., 2017). Research also aims to identify thunderstorm precursors and climate changes.

The second objective concerns the thunderstorm loading and response of structures. Two anemometer towers will be equipped by accelerometers and strain-gauges to detect simultaneously wind velocity and response. Three complementary methods will be developed to evaluate the wind loading of structures: time-domain analysis, response spectrum technique and EPSD. The classic unique wind loading will be separated into two conditions, one for cyclones and the other for downbursts, producing a new set of partial and combination factors. An archive of structure test-cases will be gathered and wind loading will be evaluated by the classical method and the new loading format. Additional costs and savings will be estimated. Structures and climates for which classic analyses lead to unsafe design or excessive caution will be identified.

The third objective concerns dissemination and involves some new ideas to create a vast involvement of the international scientific community and, even more, its direct support to the project itself. An open-website catalogue of thunderstorm outflows will be created (2018); an International Advanced School (2020) and an International Workshop (2022) on "Thunderstorm outflows and their impact on structures" will be held in Genoa, Italy. International Awards will be also awarded (2022).

Acknowledgements This research is funded by the European Research Council (ERC) under the European Union's Horizon 2020 research and innovation program (grant agreement No. 741273) for the project THUNDERR - Detection, simulation, modelling and loading of thunderstorm outflows to design wind-safer and costefficient structures - supported by an Advanced Grant 2016. 


\section{References}

Abd-Elaal, E., Mills, J.E., and Ma, X. (2013a). An analytical model for simulating steady state flows of downburst. Journal of Wind Engineering and Industrial Aerodynamics 115, 53-64.

Abd-Elaal, E.S., Mills, J.E., and Ma, X. (2013b). A coupled parametric-CFD study for determining ages of downbursts through investigation of different field parameters. Journal of Wind Engineering and Industrial Aerodynamics 123, 30-42.

Aboshosha, H., Bitsuamlak, G., and El Damatty, A. (2015). Turbulence characterization of downbursts using LES. Journal of Wind Engineering and Industrial Aerodynamics 136, 44-61.

Alahyari, A., and Longmire, E.K. (1995). Dynamics of experimentally simulated microburst. AIAA Journal 33, 2128-2136.

American Society of Civil Engineers (1961). Wind forces on structures. Transactions ASCE II, 1124-1198.

Bakke, P. (1957). An experimental investigation of a wall jet. Journal of Fluid Mechanics $125,467-472$.

Blocken, B. (2014). 50 years of Computational Wind Engineering: past, present and future. Journal of Wind Engineering and Industrial Aerodynamics 129, 69-102.

Brooks, H.E., Lee, J.W., and Craven, J.P. (2003). The spatial distribution of severe thunderstorm and tornado environments from global reanalysis data. Atmospheric Research 67-68, 73-94.

Burlando, M., Romanic, D., Solari, G., Hangan, H., and Zhang, S. (2017). Field data analysis and weather scenario of a downburst event in Livorno, Italy on 1 October 2012. Monthly Weather Review 145, 3507-3527.

Byers, H.R., and Braham, R.R. (1949). The thunderstorm: Final report of the Thunderstorm Project. U.S. Government Printing Office, Washington, DC.

Cao, S., Nishi, A., and Kikugawa, H. (2002). Reproduction of wind velocity history in a multiple fan wind tunnel. Journal of Wind Engineering and Industrial Aerodynamics 90, 1719-1729.

Cermak, J.E. (1975). Applications of fluid mechanics to wind engineering - A Freeman Scholar Lecture. Journal of Fluids Engineering ASME 97, 9-38.

Chay, M.T., and Letchford, C.W. (2002). Pressure distributions on a cube in a simulated thunderstorm downburst. Part A: stationary downburst observations. Journal of Wind Engineering and Industrial Aerodynamics 90, 711-732.

Chay, M.T., Albermani, F., and Wilson, B. (2006). Numerical and analytical simulation of downburst wind loads. Engineering Structures 28: 240-254.

Chay, M.T., Wilson, R., and Albermani, F (2008). Gust occurrence in simulated nonstationary winds. Journal of Wind Engineering and Industrial Aerodynamics 96, 2161-2172.

Chen, L., and Letchford, C.W. (2004a). A deterministic-stochastic hybrid model of downbursts and its impact on a cantilevered structure. Engineering Structures 26, 619-629.

Chen, L., and Letchford, C.W. (2004b). Parametric study on the alongwind response of the CAARC building to downbursts in the time domain. Journal of Wind Engineering and Industrial Aerodynamics 92, 703-724. 
Chen, L., and Letchford, C.W. (2006). Multi-scale correlation analyses of two lateral profiles of full-scale downburst wind speeds. Journal of Wind Engineering and Industrial Aerodynamics 94, 675-696.

Chen, L., and Letchford, C.W. (2007). Numerical simulation of extreme winds from thunderstorm downbursts. Journal of Wind Engineering and Industrial Aerodynamics 95, 977-990.

Chen, X. (2008). Analysis of alongwind tall building response to transient nonstationary winds. Journal of Structural Engineering ASCE 134, 782-791.

Chen, X. (2015). Analysis of multimode coupled buffeting response of long-span bridges to non-stationary winds with force parameters from stationary wind. Journal of Structural Engineering ASCE 141, 04014131.

Choi, E.C.C. (1999). Extreme wind characteristics over Singapore - an area in the equatorial belt. Journal of Wind Engineering and Industrial Aerodynamics 83, 61-69.

Choi, E.C.C. (2004). Field measurement and experimental study of wind speed during thunderstorms. Journal of Wind Engineering and Industrial Aerodynamics 92, 275-290.

Choi, E.C.C., and Tanurdjaja, A. (2002). Extreme wind studies in Singapore. An area with mixed weather system. Journal of Wind Engineering and Industrial Aerodynamics 90, 1611-1630.

Choi, E.C.C., and Hidayat, F.A. (2002a). Gust factors for thunderstorm and non-thunderstorm winds. Journal of Wind Engineering and Industrial Aerodynamics 90, 1683-1696.

Choi, E.C.C., and Hidayat, F.A. (2002b). Dynamic response of structures to thunderstorm winds. Progress in Structural Engineering and Materials 4, 408-416.

Darwish, M.M., El Damatty, A., and Hangan, H. (2010). Dynamic characteristics of transmission line conductors and bahaviour under turbulent downburst loading. Wind and Structures $13,327-346$.

Davenport, A.G. (1961). The application of statistical concepts to the wind loading of structures. Proceedings of the Institution of Civil Engineers 19, 449-472.

Davenport, A.G. (1968). The dependence of wind loads on meteorological parameters. International Research Seminar on Wind effects on Buildings and Structures, Ottawa, Canada, 1967, I, 19-82.

De Coning, E., Koenig, M., Olivier, J. (2011). The combined instability index: a new veryshort range convection forecasting technique for southern Africa. Meteorological Applications $18,421-439$.

De Gaetano, P., Repetto, M.P., Repetto, T., and Solari, G. (2014). Separation and classification of extreme wind events from anemometric records. Journal of Wind Engineering and Industrial Aerodynamics 126, 132-143.

Didden, N., and Ho, C.M. (1985). Unsteady separation in a boundary layer produced by an impinging jet. Journal of Fluid Mechanics 160, 235-256.

Donaldson, C.D., and Snedeker, R.S. (1971). A study of free jet impingement. Part 1. Mean properties of free and impinging jet. Journal of Fluid Mechanics 45, 235-256.

Duranona, V., Sterling, M., and Baker, C.J. (2006). An analysis of extreme non-synoptic winds. Journal of Wind Engineering and Industrial Aerodynamics 95, 1007-1027. 
Elawadi, A., Aboshosha, H., El Damatty, A., Bitsuamlak, G., Hangan, H., and Elatar, A. (2017). Aero-elastic testing of multi-spanned transmission line subjected to downbursts. Journal of Wind Engineering and Industrial Aerodynamics 169, 194-216.

Fujita, T.T. (1985). Downburst: microburst and macroburst. University of Chicago Press, Chicago, IL.

Fujita, T.T. (1990). Downburst: meteorological features and wind field characteristics. Journal of Wind Engineering and Industrial Aerodynamics 36, 75-86.

Fujita, T.T., and Wakimoto, R.M. (1981). Five scales of airflow associated with a series of downbursts on 16 July 1980. Monthly Weather Review 109, 1438-1456.

Giorgi, F., Whetton, P. H., Jones, R.G., Christensen, J. H., Mearns, L. O., Hewitson, B., vonStorch, H., Francisco, R., and Jack, C. (2001). Emerging patterns of simulated regional climatic changes for the 21st century due to anthropogenic forcings. Geophysical Research Letters 28, 3317-3320.

Glauert, M.B. (1956). The wall jet. Journal of Fluid Mechanics 1, 625-643.

Goff, R.G. (1976). Vertical structure of thunderstorm outflows. Monthly Weather Review 104, $1429-1440$

Gomes, L., and Vickery, B.J. (1976). On thunderstorm wind gusts in Australia. Civil Engineering Tansactions Australia 18, 33-39.

Gomes, L., and Vickery, B.J. (1977/1978). Extreme wind speeds in mixed climates. Journal of Industrial Aerodynamics 2, 331-344.

Gunter, W.S., and Schroeder, J.L. (2015). High-resolution full-scale measurements of thunderstorm outflow winds. Journal of Wind Engineering and Industrial Aerodynamics 138, 13-26.

Haklander, A.J., and Van Delden, A. (2003). Thunderstorm predictors and their forecast skill for the Netherlands, Atmospheric Research 67-68, 273-299.

Hangan, H., Refan, M., Jubayer, C., Romanic, D., Parvu, D., Lo Tufo, J., and Costache, A. (2017). Novel techniques in wind engineering. Journal of Wind Engineering and Industrial Aerodynamics 171, 12-33.

Hjelmfelt, M.R. (1988). Structure and life cycle of microburst outflows observed in Colorado. Journal of Applied Meteorology 27, 900-927.

Hjelmfelt, M.R., Roberts, R.D., Orville, H.D., Chen, J.P., and Kopp, F.J. (1989). Observational and numerical study of a microburst line-producing storm. Journal of Atmospheric Sciences 46, 2713-2744.

Holmes, J.D., and Oliver, S.E. (2000). An empirical model of a downburst. Journal of Industrial Aerodynamics 22, 1167-1172.

Holmes, J.D., Hangan, H.M., Schroeder, J.L., Letchford, C.W., and Orwig, K.D. (2008). A forensic study of the Lubbock-Reese downdraft of 2002. Wind and Structures 11, 19-39.

Huang, G., and Chen, X. (2009). Wavelets-based estimation of multivariate evolutionary spectra and its application to nonstationary downburst winds. Engineering Structures 31, 976-989.

Huang, G., Zheng, H., Xu, Y.L., and Li, Y. (2015). Spectrum models for non-stationary extreme winds. Journal of Structural Engineering ASCE 141, 04015010. 
Huntrieser, H., Schiesser, H.H., Schmid, W., and Waldvogel, A. (1997). Comparison of Traditional and Newly Developed Thunderstorm Indices for Switzerland, Weather and Forecasting 12, 108-125.

Ivan, M. (1986). A ring-vortex downburst model for flight simulations. Journal of Aircraft 23, 232-236.

Jacob, D., and Coauthors (2014). EURO-CORDEX: New high-resolution climate change projections for European impact research. Regional Environmental Change 14, 563-578.

Jesson, M., Sterling, M., Letchford, C., and Baker, C. (2015). Aerodynamic forces on the roofs of low-, mid- and high-rise buildings subject to transient winds. Journal of Wind Engineering and Industrial Aerodynamics 143, 42-49.

Kareem, A., Guo, Y., and Hu, L. (2016). Time-frequency modeling framework for nonstationary aerodynamic load effects. 8th International Colloquium on Bluff-Body Aerodynamics and Applications, Boston, MA.

Karman, T. Von. (1948). L'aerodynamique dans l'art de ingénieur. Mémoires de la Société des Ingenieurs Civils de France, 155-178.

Kasperski, M. (2002). A new wind zone map of Germany. Journal of Wind Engineering and Industrial Aerodynamics 90, 1271-1287.

Katsura, J. (1997). Some conceptions for the flow pattern formation around bluff bodies in natural winds. Journal of Wind Engineering and Industrial Aerodynamics 66, 1-15.

Kim, J., and Hangan, H. (2007). Numerical simulations of impinging jets with application to downbursts. Journal of Wind Engineering and Industrial Aerodynamics 95, 279-298.

Knupp, K.R. (1989). Numerical simulation of low-level downdraft initiation within precipitating cumulonimbi: some preliminary results. Monthly Weather Review 117, 1517-1529.

Kwon, D.K., and Kareem, A. (2009). Gust-front factor: new framework for wind load effects on structures. Journal of Structural Engineering ASCE 135, 717-732.

Le, T.H., and Caracoglia, L. (2015). Reduced-order wavelet-Galerkin solution for the coupled, nonlinear stochastic response of slender buildings in transient winds. Journal of Sound and Vibration 344, 179-208.

Letchford, C.W., and Chay, M.T. (2002). Pressure distributions on a cube in a simulated thunderstorm downburst. Part B: moving downburst observations. Journal of Wind Engineering and Industrial Aerodynamics 90, 733-753.

Letchford, C.W., Mans, C., and Chay, M.T. (2002). Thunderstorms - their importance in wind engineering (a case for the next generation wind tunnel). Journal of Wind Engineering and Industrial Aerodynamics 90, 1415-1433.

Li, C.Q. (2000). A stochastic model of severe thunderstorms for transmission line design. Probabilistic Engineering Mechanics 15, 359-364.

Li, C., Li, Q.S., Xiao, Y.Q., and Ou, J.P. (2012). A revised empirical model and CFD simulations for 3D axisymmetric steady-state flows of downbursts and impinging jets. Journal of Wind Engineering and Industrial Aerodynamics 102, 48-60.

Lin, W.E., and Savory, E. (2006). Large-scale quasi-steady modeling of a downburst outflow using a slot jet. Wind and Structures 9, 419-440. 
Lin, E.W., Orf, L.G., Savory, E., and Novacco, C. (2007). Proposed large-scale modelling of the transient features of a downburst outflow. Wind and Structures 10, 315-346.

Lombardo, F.T. (2014). Extreme wind speeds from multiple hazards excluding tropical cyclones. Wind and Structures 19, 467-480.

Lombardo, F.T., Main, J.A., and Simiu, E. (2009). Automated extraction and classification of thunderstorm and non-thunderstorm wind data for extreme-value analysis. Journal of Wind Engineering and Industrial Aerodynamics 97, 120-131.

Lombardo, F.T., Smith, D.A., Schroeder, J.L., and Mehta, K.C. (2014). Thunderstorm characteristics of importance to wind engineering. Journal of Wind Engineering and Industrial Aerodynamics $125,121-132$.

Lombardo, F.T., and Mason, M.S. (2016). Investigation of a downburst loading event on a full-scale low-rise building. 8th International Colloquium on Bluff-Body Aerodynamics and Applications, Boston, MA.

Lundgren, T.S., Yao, J., and Mansour, N.N. (1992). Microburst modelling and scaling. Journal of Fluid Mechanics 239, 461-488.

Mara, T.G., Hong, H.P., Lee, C.S., and Ho, T.C.E. (2016). Capacity of a transmission tower under downburst wind loading. Wind and Structures 22, 65-87.

Marsh, P.T., Brooks, H.E., and Karoly, D.J. (2009). Preliminary investigation into the severe thunderstorm environment of Europe simulated by the Community Climate System Model 3. Atmospheric Research 93, 607-618.

Mason, M., Letchford, C.W., and James, D.L. (2005). Pulsed jet simulation of a stationary thunderstorm downburst. Part A: Physical structure and flow field characterization. Journal of Wind Engineering and Industrial Aerodynamics 93, 557-580.

Mason, M.S., Wood, G.S., and Fletcher, D.F. (2009). Numerical simulation of downburst winds. Journal of Wind Engineering and Industrial Aerodynamics 97, 523-539.

Matsumoto, M., Shimamura, M., Maeda, T., Shirato, H., Yagi, T., Hori, K., Kawashima, Y., and Hashimoto, M. (2007). Drag forces on 2-D cylinders due to sudden increase of wind velocity. 12th International Conference on Wind Engineering, Cairns, Australia, 1727-1734.

McCann, D.W. (1994). WINDEX - A new index for forecasting microburst potential. Weather and Forecasting 9, 532- 541.

McConville, A.C., Sterling, M., and Baker, C.J. (2009). The physical simulation of thunderstorm downbursts using an impinging jet. Wind and Structures 12, 133-149.

Mitchell, K.E., and Hovermale, J.B. (1977). A numerical investigation of the severe thunderstorm gust front. Monthly Weather Review 105, 657-675.

Mohr, S., Kunz, M., Richter, A., and Ruck, B. (2017). Statistical characteristics of convective wind gusts in Germany. Natural Hazards and Earth System Science 17, 957-969.

Nicholls, M., Pielke, R., and Meroney, R. (1993). Large eddy simulation of microburst winds flowing around a building. Journal of Wind Engineering and Industrial Aerodynamics 46 $\& 47,229-237$.

Nissen, K.M., Leckebusch, G.C., Pinto, J.G., Ulbrich, U. (2014). Mediterranean cyclones and windstorms in a changing climate. Regional Environmental Change 14, 1873-1890. 
Ogura, Y. (1963). The evolution of a moist convective element in a shallow, conditionally unstable atmosphere: a numerical calculation. Journal of Atmospheric Sciences 20, 407-424.

Oliver, S.E., Moriarty, W.W., and Holmes, J.D. (2000). A risk model for design of transmission line systems against thunderstorm down burst winds. Engineering Structures 22, 1173-1179.

Orf, L.G., and Anderson, J.R. (1999). A numerical study of travelling microbursts. Journal of the Atmospheric Sciences 127, 1244-1258.

Orf, L., Kantor, E., and Savory, E. (2012). Simulation of a downburst-producing thunderstorm using a very high-resolution three-dimensional cloud model. Journal of Wind Engineering and Industrial Aerodynamics 104-106, 547-557.

Orville, H.D. (1965). A numerical study of the initiation of cumulus clouds over mountainous terrain. Journal of Atmospheric Sciences 24, 1596-1618.

Oseguera, R.M., and Bowles, R.L. (1988). A simple analytic 3-dimensional downburst model based on boundary layer stagnation flow. NASA Technical Memorandum 100632.

Pagon, W.W. (1934, 1935). Aerodynamics and the civil engineers. Engineering News Records.

Peng, L., Huang, G., Chen, X, and Kareem, A. (2017). Simulation of multivariate nonstationary random processes: hybrid stochastic wave and proper orthogonal decomposition approach Journal of Engineering Mechanics ASCE 143, 04017064.

Peng, L., Huang, G., Chen, X., and Yang, Q. (2018). Evolutionary spectra-based time-varying coherence function and application in structural response analysis to downburst winds. Journal of Structural Engineering ASCE 144, 04018078.

Piccardo, G., and Solari, G. (1998). Generalized equivalent spectrum technique. Wind and Structures 1, 161-174.

Ponte, Jr., and J., Riera, J.D. (2010). Simulation of extreme wind series caused by thunderstorms in temperate latitudes. Structural Safety 32, 131-137.

Poreh, M., Tsuel, Y.G., and Cermak, J.E. (1967). Investigation of a turbulent radial wall jet. Journal of Applied Mechanics, Transactions ASME, 34, 457-463.

Proctor, F.H. (1987a). The terminal area simulation system. I: theoretical formulation. NASA Contractor Report 4046.

Proctor, F.H. (1987b). The terminal area simulation system. II: verification cases, NASA Contractor Report 4047.

Proctor, F.H. (1988). Numerical simulations of an isolated micro burst. Part I: dynamics and structure. Journal of the Atmospheric Sciences 45, 3137-3159.

Proctor, F.H. (1989). Numerical simulations of an isolated microburst. Part II: Sensitivity experiments. Journal of the Atmospheric Sciences 46, 2143-2165.

Púcik, T., Groenemeijer, P., Rädler, A.T., Tijssen, L., Nikulin, G., Prein, A.F., Van Meijgaard, E., Fealy, R., Jacob, D., and Teichmanni, C. (2017). Future Changes in European Severe Convection Environments in a Regional Climate Model Ensemble. Journal of Climate 30, 6771-6794.

Repetto, M.P., Burlando, M., Solari, G., De Gaetano, P., and Pizzo, M. (2017). Integrated tools for improving the resilience of seaports under extreme wind events. Journal of Sustainable Cities and Societies 32, 277-294. 
Repetto, M.P., Burlando, M., Solari, G., De Gaetano, P., Pizzo, M., and Tizzi, M. (2018). A web-based GIS platform for the safe management and risk assessment of complex structural and infrastructural systems exposed to wind. Advances in Engineering Software 117, 29-45.

Richter, A., Ruck, B., Mohr, S., and Kunz, M. (2018). Interaction of severe convective gusts with a street canyon. Urban Climate 23, 71-90.

Riera, J.D., Viollaz, A.J., and Reimundin, J.C. (1977). Some recent results on probabilistic models of extreme wind speeds. Journal of Industrial Aerodynamics 2, 271-287.

Riera, J.D., and Nanni, L.F. (1989). Pilot study of extreme wind velocities in a mixed climate considering wind orientation. Journal of Wind Engineering and Industrial Aerodynamics 32, 11-20.

Sarpkaya, T. (1963). Lift, drag, and mass coefficients for a circular cylinder immersed in time dependent flow. Journal of Applied Mechanics 30, 13-15.

Selvam, R.P., and Holmes, J.D. (1992). Numerical simulation of thunderstorm downdrafts. Journal of Wind Engineering and Industrial Aerodynamics 41-44, 2817-2825.

Sengupta, A., and Sarkar, P.P. (2008). Experimental measurement and numerical simulation of an impinging jet with application to thunderstorm microburst winds. Journal of Wind Engineering and Industrial Aerodynamics 96, 345-365.

Shehata, A.Y., El Damatty, A., and Savory, E. (2005). Finite element modelling of transmission line under downburst wind loading. Finite Elements in Analysis and Design 42, 71-89.

Solari, G. (2007). The International Association for Wind Engineering (IAWE): Progress and prospect. Journal of Wind Engineering and Industrial Aerodynamics 95, 813-842.

Solari, G. (2014). Emerging issues and new frameworks for wind loading on structures in mixed climates. Wind and Structures 19, 295-320.

Solari, G., Repetto, M.P., Burlando, M., De Gaetano, P., Pizzo, M., Tizzi, M., and Parodi, M. (2012). The wind forecast for safety and management of port areas. Journal of Wind Engineering and Industrial Aerodynamics 104-106, 266-277.

Solari, G., Burlando, M., De Gaetano, P., and Repetto, M.P. (2015a). Characteristics of thunderstorms relevant to the wind loading of structures. Wind and Structures 20, 763-791.

Solari, G., De Gaetano, P., and Repetto, M.P. (2015b). Thunderstorm response spectrum: fundamentals and case study. Journal of Wind Engineering and Industrial Aerodynamics 143, 62-77.

Solari, G. (2016). Thunderstorm response spectrum technique: theory and applications. Engineering Structures 108, 28-46.

Solari, G., Rainisio, D., and De Gaetano, P. (2017). Hybrid simulation of thunderstorm outflows and wind-excited response of structures. Meccanica 52, 3197-3220.

Steiner, J.T. (1973). A three-dimensional model of cumulus cloud development. Journal of Atmospheric Sciences 30, 414-435.

Stengel, D., and Klaus, T. (2017). Measurements of downburst wind loading acting on an overhead transmission line in Northern Germany. Procedia Engineering 199, 3152-3157.

Straka, J.M., and Anderson, J.R. (1993). Numerical simulations of microburst producing storms: some results from storms observed during COHMEX. Journal of Atmospheric Sciences 50, 1329-1348. 
Twisdale, L.A., and Vickery, P.J. (1992). Research on thunderstorm wind design parameters. Journal of Wind Engineering and Industrial Aerodynamics 41, 545-556.

Vermeire, B.C., Orf, L.G., and Savory, E. (2011). Improved modeling of downburst outflows for wind engineering applications using a cooling source approach. Journal of Wind Engineering and Industrial Aerodynamics 99, 801-814.

Vicroy, D.D. (1992). Assessment of micro burst models for downdraft estimation. Journal of Aircraft 29, 1043-1048.

Wang, L., McCullough, M., and Kareem, A. (2013). A data-driven approach for simulation of full-scale downburst wind speeds. Journal of Wind Engineering and Industrial Aerodynamics 123, 171-190.

Wang., L., McCullough, M., and Kareem, A. (2014). Modelling and simulation of nonstationary processes utilizing wavelet and Hilbert transforms. Journal of Engineering Mechanics ASCE 140, 345-360.

Wang, D., Chen, X., and Xu, K. (2017). Analysis of buffeting response of hinged overhead transmission conductor to nonstationary winds. Engineering Structures 147, 567-582.

Wilson, J.W., Roberts, R.D., Kessinger C., and McCarthy, J. (1984). Microburst wind structure and evaluation of Doppler radar for airport wind shear detection., Journal of Climate and Applied Meteorology 23, 898-915.

Wittingham, H.E. (1964). Extreme wind gusts in Australia. Bulletin 46, Commonwealth Australian Bureau of Meteorology.

Wood, G.S., Kwok, K.C.S., Motteram, N.A., and Fletcher, D.F. (2001). Physical and numerical modelling of thunderstorm downburst. Journal of Wind Engineering and Industrial Aerodynamics 89, 535-552.

$\mathrm{Xu}, \mathrm{Z}$., and Hangan, H. (2008). Scale, boundary and inlet condition effects on impinging jets. Journal of Wind Engineering and Industrial Aerodynamics 96, 2383-2402.

Yang, S.C., and Hong, H.P. (2016). Nonlinear inelastic responses of transmission tower-line system under downburst wind. Engineering Structures 123, 490-500.

Zhang, Y., Hu, H., and Sarkar, P.P. (2013). Modeling of microburst outflows using impinging jet and cooling source approaches and their comparison. Engineering Structures 56, 779-793.

Zhang, Y., Sarkar, P., and Hu, H. (2013). An experimental study of flow fields and wind loads on gable-roof building models in microburst-like wind. Experiment in Fluids 54, 1511.

Zhang, Y., Sarkar, P., and Hu, H. (2014). An experimental study on wind loads acting on a high-rise building model induced by microburst-like winds. Journal of Fluids and Structures 50, 547-564.

Zhang, S., Solari, G., De Gaetano, P., Burlando, M., and Repetto, M.P. (2018a). A refined analysis of thunderstorm outflow characteristics relevant to the wind loading of structures. Probabilistic Engineering Mechanics 54, 9-24.

Zhang, S., Solari, G., Yang, Q., and Repetto, M.P. (2018b). Extreme wind speed distribution in a mixed wind climate. Journal of Wind Engineering and Industrial Aerodynamics 176, 239-253.

Zhu, S., and Etkin, B. (1985). Model of the wind field in a downburst. Journal of Aircraft 22, 595-601. 